\title{
Mycotoxin Biodegradation Ability of the Cupriavidus Genus
}

\author{
Mohammed AL-Nussairawi ${ }^{1}$ - Anita Risa ${ }^{1}$ - Edina Garai ${ }^{2}$ - Emese Varga ${ }^{3}$. István Szabó ${ }^{1} \cdot$ Zsolt Csenki-Bakos $^{1}$. \\ Balázs Kriszt ${ }^{1} \cdot$ Mátyás Cserháti $^{1}$
}

Received: 6 December 2019 / Accepted: 27 May 2020 / Published online: 5 June 2020

(c) The Author(s) 2020

\begin{abstract}
The biodegradation and biodetoxification ability of five prominent mycotoxins, namely aflatoxin B1 (AFB1), ochratoxin-A (OTA), zearalenone (ZON), T-2 toxin (T-2) and deoxynivalenol (DON) of Cupriavidus genus were investigated. Biological methods are the most appropriate approach to detoxify mycotoxins. The Cupriavidus genus has resistance to heavy metals and can be found in several niches such as root nodules and aquatic environments. The genus has 17 type strains, 16 of which have been investigated in the present study. According to the results, seven type strains can degrade OTA, four strains can degrade AFB1, four strains can degrade ZON and three strains can degrade T-2. None of the strains can degrade DON. The biodetoxification was measured using different biotests. SOS-chromotest was used for detecting the genotoxicity of AFB1, the BLYES test was used to evaluate the oestrogenicity of ZON, and the zebrafish embryo microinjection test was conducted to observe the teratogenicity of OTA, T-2 and their by-products. Two type strains, namely C. laharis CCUG $53908^{\mathrm{T}}$ and $C$. oxalaticus JCM $11285^{\mathrm{T}}$ reduced the genotoxicity of AFB1, whilst $C$. basilensis DSM $11853^{\mathrm{T}}$ decreased the oestrogenic of ZON. There were strains which were able to biodegrade more than two mycotoxins. Two strains degraded two mycotoxins, namely C. metalliduriens CCUG $13724^{\mathrm{T}}$ (AFB1, T-2) and C. oxalaticus (AFB1, ZON) whilst two strains C. pinatubonensis DSM $19553^{\mathrm{T}}$ and $C$. basilensis degraded three toxins (ZON, OTA, T-2) and C. numazuensis DSM $15562^{\mathrm{T}}$ degraded four mycotoxins (AFB1, ZON, OTA, T-2), which is unique a phenomenon amongst bacteria.
\end{abstract}

\section{Introduction}

The genus Cupriavidus was identified in 2004 [1]. Members of this genus are gram negative, chemoorganotrophic and facultative chemolithotrophic bacteria that can be found in several diverse habitats such as soil, root nodules and aquatic environments. The genus Cupriavidus belongs to

Electronic supplementary material The online version of this article (https://doi.org/10.1007/s00284-020-02063-7) contains supplementary material, which is available to authorized users.

Mátyás Cserháti

Cserhati.matyas@mkk.szie.hu

1 Department of Environmental Safety and Ecotoxicology, Faculty of Agricultural and Environmental Sciences, Szent István University, 1 Páter Károly Street, Gödöllő 2100, Hungary

2 Department of Aquaculture, Faculty of Agricultural and Environmental Sciences, Szent István University, 1 Páter Károly Street, Gödöllő 2100, Hungary

3 Department of Applied Chemistry, Faculty of Food Sciences, Szent István University, Villanyi Road, Budapest 1118, Hungary the family Burkholderiaceae and the class $\beta$-proteobacteria. Remarkable heavy metal tolerance of environmental isolates has been confirmed $[2,3]$ and some species have important xenobiotic degradation potential such as $C$. necator, which is able to degrade chlorinated aromatic compounds [4-6]. An environmental strain, $C$. basilensis ŐR16 can degrade $98 \%$ of ochratoxin-A [7] (Table 1). One strain from the $C$. taiwaniensis species can initiate root nodule formation and nitrogen fixation [8]. A member of C. respiraculi was isolated from the respiratory tract of a cystic fibrosis patient [1].

To date, 11 Cupriavidus genome projects are known for the following strains, namely C. necator CCUG $52238^{\mathrm{T}}$, C. metallidurans CCUG $13724^{\mathrm{T}}$, C. pinatubonensis DSM19553 ${ }^{\mathrm{T}}$, C. alkaliphilus BCCM $26294^{\mathrm{T}}$, C. basileneis DSM $11853^{\mathrm{T}}$, C. oxalaticus JCM $11285^{\mathrm{T}}$, C. pauculus JCM $11286^{\mathrm{T}}$, C. taiwanensis CCUG $44338^{\mathrm{T}}$, C. campinensis CCUG $44526^{\mathrm{T}}$, C. nantongensis KCTC $42909^{\mathrm{T}}$ and C. plantarum BCCM/LMG $26296^{\mathrm{T}}$. The genome size of the genus varies from 6.5 to $8.5 \mathrm{Mbp}$ [21]. Genomic sequences suggest that the species has significant catabolic potential, as several pathways responsible for aromatic ring cleavage have been identified, such as the catechol and protocatole ortho-ring 
Table 1 Xenobiotic biodegradation ability of the Cupriavidus genus strains

\begin{tabular}{|c|c|c|c|c|}
\hline Species & Strain & Isolation matrix & Biodegraded chemicals & References \\
\hline \multirow[t]{2}{*}{ C. necator } & NH9 & Contaminated soil, Japan & $\begin{array}{l}\text { Chlorinated aromatic chemicals; halo benzoate } \\
\text { and nitrophenols }\end{array}$ & {$[9,10]$} \\
\hline & JMP134 & Soil, unknown & $2,4-\mathrm{D}$ & {$[6]$} \\
\hline C. numazuensis & TE $26^{\mathrm{T}}$ & $\begin{array}{l}\text { Natural soil, Japan, Numazu city, Shizuoka } \\
\text { prefecture }\end{array}$ & $\begin{array}{l}\text { Trichloroethylene, cis-dichloroethylene and } \\
\text { toluene }\end{array}$ & {$[11]$} \\
\hline \multirow[t]{7}{*}{ C. basilensis } & HMF14 & Soil, Netherlands & Hydroxymetyl-furfural (HMF) & {$[12]$} \\
\hline & JF1 & BPA-degrading planted fixed-bed reactor & Bisphenol-A & {$[13]$} \\
\hline & M91-3 & Agricultural soil & Atrazine & {$[14]$} \\
\hline & $\mathrm{R} 25 \mathrm{C} 6$ & PCP-contaminated soil, Ljungby, Sweden & Chlorobenzene, phenol & {$[15]$} \\
\hline & B-8 & Erosive bamboo slips, China & Kraft lignin biodegradation & {$[16]$} \\
\hline & ÖR16 & Natural soil, Hungary & Ochratoxin-A & {$[7]$} \\
\hline & RK1 & Freshwater pond, France & 2,6-dichlorophenol & {$[17]$} \\
\hline C. gilardi & CR3 & Rancho La Brea Tar Pits 91, Los Angeles & Naphthenic acids & {$[18]$} \\
\hline C. pauculus & KF709 & Biphenyl-contaminated soil in Kitakyushu, Japan & Biphenyl & [19] \\
\hline C. nantongensis & $\mathrm{X} 1^{\mathrm{T}}$ & $\begin{array}{l}\text { Sludge, chlorpyrifos manufacture plant Nantong, } \\
\text { China }\end{array}$ & Chlorpyrifos & {$[20]$} \\
\hline C. pampae & $C P D B 6^{\mathrm{T}}$ & $\begin{array}{l}\text { Agricultural soil, Argentinean Humid Pampa } \\
\text { region }\end{array}$ & $2,4-\mathrm{D}$ & {$[5]$} \\
\hline
\end{tabular}

cleavage, catechol meta-position ring cleavage, gentisate and benzene-CoA pathways [22] (Table 1).

The genus has 17 type strains, from which the biodegradation and detoxification potential of 16 has been investigated for five mycotoxins, namely aflatoxin B1 (AFB1), ochratoxin-A (OTA), zearalenone (ZON), T-2 toxin (T-2) and deoxynivalenol (DON). Figure 1 depicts the phylogenetic tree of the Cupriavidus genus type strains.

Contamination of food and feed by toxigenic moulds (fungi) is an increasing and unavoidable problem because the climatic extremities cause permanent stress for the crops, which becomes vulnerable to fungi. This leads to an increase in the number of mycotoxin contaminations amongst foodstuff globally [23, 24]. However, there are approximately 300 to 400 different identified mycotoxins. In the present study, five toxins will be investigated because they have a negative influence on human and animal health, such as genotoxicity, oestrogenity, nephrotoxicity and teratogenicity.

A limited number of methods have been developed to degrade mycotoxins and/or reduce their toxicity. Ozonation [25] can be applied as a chemical method. Sorting, extrusion and application of adsorbents are physical techniques
Fig. 1 Neighbour-joining tree based on 16S rRNA gene sequences showing the phylogenetic relations of 17 type strains of Cupriavidus genus with AFB1, OTA, ZEA and T-2 detoxification ability. Bootstrap values are presented as percentages of 1000 replicates. Only values above $50 \%$ were shown. The tree analysis was conducted in MEGA7 software

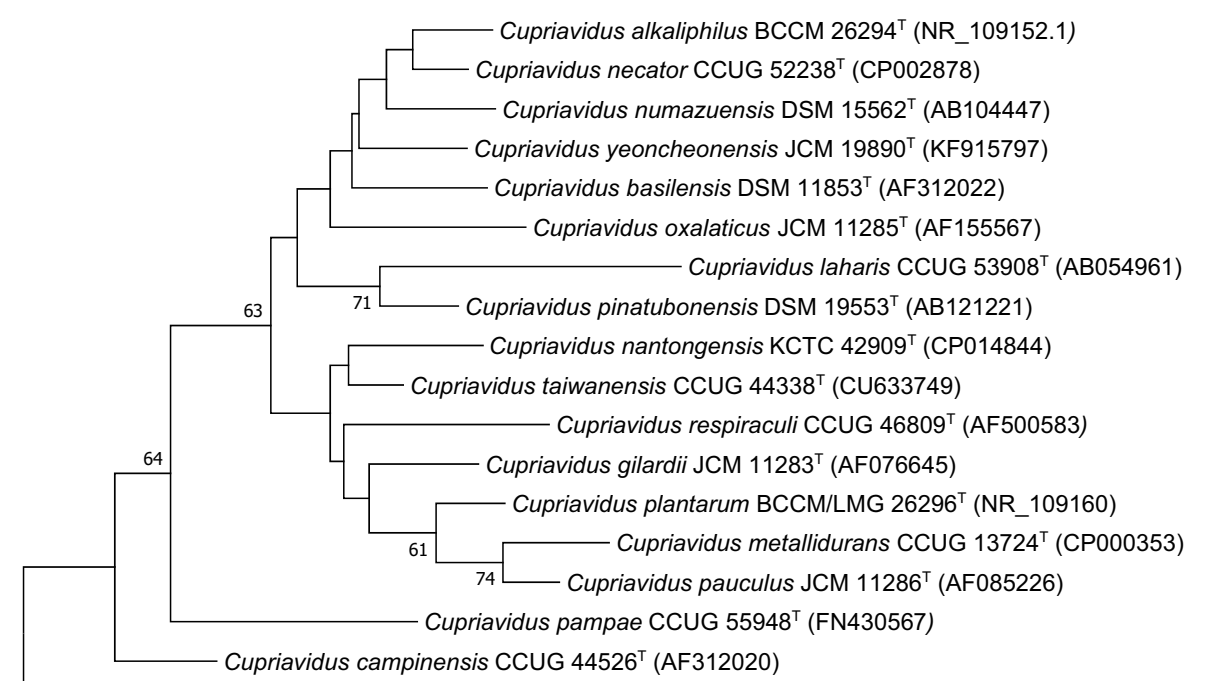

Ralstonia pickettii ATCC 27511 DP23 (JOVL01000020) 
[26] whilst biological methods include the biodegradation by microorganisms or their enzymes. The treatment of feed products by adsorbents such as bentonite and clay can efficiently bind toxins [27] although in the animal intestinal tract, these agents can also adsorb vitamins and nutrients [28].

The biodegradation of mycotoxins by different bacteria is a widely used method for decreasing their concentrations. The biodegradation is not synonymous with biodetoxification, and this phenomenon should be investigated in all cases of biodegradation. During the biodegradation, the byproduct can be more toxic or harmful then the initial chemical. However, the investigation of the by-product toxicity is not straightforward. Biotests are useful for evaluating the detoxification efficiency and prior to making any product suitable for the market, detoxification from different biotests or assays is advised to determine the difference between the sensitiveness and behaviour of the test organism. However, detoxification is an appropriate way of treating contaminated feed and foodstuff.

\section{Materials and Methods}

\section{Cupriavidus Strains and Mycotoxin Stock Solutions}

Sixteen type strains of the genus Cupriavidus were purchased from the following strain collections, namely the Deutsche Sammlung von Mikroorganizmen und Zellculturen (DSMZ) (German Collection of Microorganism and Cell Cultures), the Japan Collection of Microorganisms (JCM), the Culture Collection University of Gothenburg (CCUG), Sweden and the Belgian Coordinated Collection of Microorganisms (BCCM). The 17th type strain C. nantongensis KCTC $42909^{\mathrm{T}}$ from South Korea could not been ordered in time for the experiments. Mycotoxins were purchased from Sigma Aldrich Limited (Budapest, Hungary). From these mycotoxins, $1 \mathrm{mg} / \mathrm{mL}$ of stock solutions were prepared in acetone and used in degradation experiments.

\section{Chemicals and Reagents}

With regards to the HPLC-MS/MS analysis, all standards and reagents were purchased from the Hungarian distributors of national companies. Mycotoxin standards with minimum $98 \%$ purity were purchased from Romer Labs (Hungary). Mobile phases and extraction solvents were used containing super gradient grade acetonitrile $(\mathrm{MeCN}$, 99\%) purchased from VWR (Hungary), gradient grade methanol $\left(\mathrm{CH}_{3} \mathrm{OH}, 99 \%\right)$ obtained from Fischer Scientific (Budapest), ultra-pure-grade water $(18 \mathrm{M} \Omega \mathrm{cm})$ produced inhouse by a Milli-Q water purification system (Merck, Darmstadt, Germany). Acetic acid $\left(\mathrm{CH}_{3} \mathrm{COOH}, 99.8 \%\right)$ obtained from Merck (Hungary), formic acid $(\mathrm{HCOOH}, 98 \%)$ from Scharlau (Hungary) and LC/MS grade ammonium-acetate $\left(\mathrm{CH}_{3} \mathrm{COONH}_{4},>99 \%\right)$ from VWR (Hungary). Luria-Bertani (LB) media and acetone were ordered from BioLab Incorporated and Reanal Ltd Hungary.

\section{Biodegradation Experiments}

Cupriavidus strains were stored at $-80^{\circ} \mathrm{C}$ and were streaked on LB agar plates ( $10 \mathrm{~g}$ tryptone, $5 \mathrm{~g}$ yeast extract, $9 \mathrm{~g} \mathrm{NaCl}$ and $18 \mathrm{~g}$ bacteriological agar dissolved in $1000 \mathrm{~mL}$ distilled water). The plates were incubated at $28{ }^{\circ} \mathrm{C}$ for three days for colony forming. A single colony was inoculated into Erlenmeyer flasks containing $50 \mathrm{~mL}$ liquid TGE-5 medium (5 g tryptone, $5 \mathrm{~g}$ glucose and $2.5 \mathrm{~g}$ yeast extract dissolved in $1000 \mathrm{~mL}$ distilled water). The flasks were incubated at $28^{\circ} \mathrm{C}$ (Sartorius AG, Germany). After three days, the optical density of the cultures was measured by an UV-Vis spectrophotometer (Genesys 10 UV-Vis, Thermo Fisher Scientific Incorporated, US) and adjusted to OD600 $=1.0$. From this culture, $5 \mathrm{~mL}$ was inoculated into $45 \mathrm{~mL}$ freshly sterilized LB medium, which was inserted with the stock solution of the mycotoxins, $1 \mu \mathrm{g} / \mathrm{mL}$ initial concentration in each mycotoxin. The monotoxins experiment was conducted in triplicates. $50 \mathrm{~mL}$ sterile LB medium containing the mycotoxin was applied as a microbe-free control. Flasks were incubated at $28{ }^{\circ} \mathrm{C}$ for five days, thereafter, $1 \mathrm{~mL}$ samples were taken and centrifuged at 20,800 $\times g$ for $15 \mathrm{~min}$ (Eppendorf 5810R Centrifuge, Eppendorf, Germany). Supernatants and pellets were separated and stored at $-80^{\circ} \mathrm{C}$ for further HPLC MS/ MS analysis.

\section{Genotoxicity Test}

The genotoxic effect in supernatant samples was observed by the colorimetric SOS-chromotest (Environmental BioDetection Products Incorporated, Canada). In the genetically modified test organism, E. coli $\mathrm{PQ} 37$, operon fusion of sfiA and lac Z genes was conducted. As a result, when the SOS-repair mechanism commenced, $\beta$-galactosidase was produced simultaneously, which was proportional to the strength of the genotoxicity [29]. The test was conducted according to the description of Risa et al. [30]. The genotoxic effect was expressed in induction factor (IF), which was calculated according to Eq. (1) [31]:

Induction factor $(\mathrm{IF})=(\mathrm{C} 405 * \mathrm{~S} 620) /(\mathrm{S} 405 * \mathrm{C} 620)$

where $C$ is the mean of the absorbance value of the control and $\mathrm{S}$ is the mean of the absorbance value of the sample measured at 405 and $620 \mathrm{~nm}$ wavelength.

Samples were considered as not genotoxic, when IF was significantly $(p<0.05)$ less than 1.5 [32]. 


\section{Oestrogenicity Test}

With regards to the detection of the oestrogenic effect of ZON and its metabolites, the bioluminescence-based BLYES test was used [33]. The Saccharomyces cerevisiae BLYES strain had been genetically modified, inserting gene encoding human estrogenic receptor, lux genes and estrogenic response element into its genome. This modification made the BLYES strain capable of emitting light after an oestrogenic compound binds to the oestrogenic receptor. The test was conducted in accordance with Risa et al. [31]. The oestrogenic effect was expressed in bioluminescence intensification (\%), which was calculated according to Eq. (2) [34]:

Bioluminescence intensication $(\%)=(-1) *((\mathrm{C}-\mathrm{S}) / \mathrm{C}) * 100$

where $C$ is the mean of the bioluminescence values of the negative control and $\mathrm{S}$ is the mean of the bioluminescence values of the sample.

\section{Zebrafish Microinjection Tests for OTA and T-2}

\section{Preparation of the Bacterial Inocula}

Bacterial inocula $(5 \mathrm{~mL})$ was prepared as stated and added to $45 \mathrm{~mL} 20 \% \mathrm{LB}$ medium containing OTA and T-2 separately (monotoxic) (7 mg/L final concentration). Similar inocula were prepared in parallel without mycotoxins to test the effects of bacterial metabolites. Uninoculated LB medium (20\%) was combined with OTA and T2 (7 mg/L) was used as a negative control. Both of the cultures and controls were incubated at $28{ }^{\circ} \mathrm{C}, 170 \mathrm{rpm}$ for $120 \mathrm{~h}$ in triplicates. After the incubation, cultures were centrifuged at $14,000 \times g, 4{ }^{\circ} \mathrm{C}$ for $15 \mathrm{~min}$. Supernatants were filtered with $0.2 \mu \mathrm{m}$ syringe filters, and samples were stored at $-20{ }^{\circ} \mathrm{C}$ until microinjection.

\section{Microinjection}

\section{Animal Protection}

The animal protocol was approved under the Hungarian law regarding animal welfare (XIV-I-001/2303-4/2012) and all studies were completed before the treated individuals would have reached the free feeding stage.

\section{Zebrafish Maintenance and Egg Collection}

Laboratory-bred wild type $A B$ strain zebrafish were held in breeding groups of 30 females and 30 males at the Department of Aquaculture, Szent István University,
Hungary, in a Tecniplast ZebTEC recirculation system (Tecniplast S.p.A., Italy) at $25.5^{\circ} \mathrm{C} \pm 0.5^{\circ} \mathrm{C}, \mathrm{pH} 7.0 \pm 0.2$, conductivity $550 \pm 50 \mu \mathrm{S}$ (system water) and a light: dark period of $14 \mathrm{~h}: 10 \mathrm{~h}$. The fish were fed twice a day with dry granulate food (Zebrafeed 400-600 $\mu \mathrm{m}$, Sparos Lda., Portugal) supplemented with freshly hatched live Artemia salina once a day. The fish were placed in breeding tanks (Tecniplast S.p.a.) late in the afternoon the day before the experiment and allowed to spawn by removing the dividing walls the following morning. Spawning of individual pairs was delayed to allow for a continuous supply of 1 -cell embryos.

\section{Microinjection}

Microinjection was conducted as described by Csenki et al. [35]. The changes were in the volume of injection, namely the sphere diameter of $50 \mu \mathrm{m}$ corresponded to an injection volume of $0.074 \mathrm{~nL}, 75 \mu \mathrm{m}$ to $0.22 \mathrm{~nL}$, and $200 \mu \mathrm{m}$ to 4.17 $\mathrm{nL}$.

\section{Experimental Design}

Bacteria metabolites were injected with $4.17 \mathrm{~nL}$ volume in three replicates (20 eggs per replicate). $7 \mathrm{mg} / \mathrm{L} \mathrm{T}-2$ toxin and bacteria $\mathrm{T}-2$ toxin degradation products were injected with $0.074 \mathrm{~nL}$ and $4.17 \mathrm{~nL}$ volumes in three replicates (20 eggs per replicate). $7 \mathrm{mg} / \mathrm{L}$ OTA toxin and bacteria OTA toxin degradation products were injected with $0.22 \mathrm{~nL}$ and $4.17 \mathrm{~nL}$ volumes in three replicates (20 eggs per replicate).

\section{Examination of Injected Embryos}

Embryo mortality was determined at $120 \mathrm{hpf}$ based on egg coagulation, the lack of somite formation and the lack of heart function.

\section{Analytical Measurements}

High-performance liquid chromatography with tandem mass spectrometry (HPLC-MS/MS) was conducted for the measurement of AFB1, ZON, OTA, T-2 and DON concentrations. From the three experiments' culture, lombics 1-1 mL inocula was taken as a sample, centrifuged for $20 \mathrm{~min}$ at $4000 \mathrm{rpm}$, and the supernatant and pellet separated. In terms of the supernatants, $500 \mu \mathrm{L}$ was transferred into $1.5 \mathrm{~mL}$ vials, then evaporated, reconstituted with $\mathrm{A} / \mathrm{B}$ eluent (50:50\%) and injected directly into the HPLC-MS/ MS. In terms of the pellet $1 \mathrm{~mL}$ extraction, solvent acetonitrile/water/formic acid was added and vortexed for $1 \mathrm{~min}$. Subsequently, $500 \mu \mathrm{L}$ of suspension was transferred to $1.5 \mathrm{~mL}$ vials then handled as supernatants. $500 \mu \mathrm{L}$ samples were evaporated until dry under a gentle N2 stream. 
Thereafter, it was reconstituted in 50-50 V/V\% A-B eluent (A: water, $5 \mathrm{mM}$ ammonium-acetate, $0.1 \%$ acetic acid; B: methanol, $5 \mathrm{mM}$ ammonium-acetate, $0.1 \%$ acetic acid) and filtered through a $0.22 \mu \mathrm{m}$ PTFE syringe filter. With regards to the chromatographic separation, an Agilent 1100 HPLC (Agilent Technologies, US) equipped with Agilent Zorbax C18 column $(3.5 \mu \mathrm{m}, \mathrm{XDB}-\mathrm{C} 18,2.1 \times 50 \mathrm{~mm})$ was used. $10 \mu \mathrm{L}$ prepared samples were injected into the mobile phase containing A-B eluent. $400 \mu \mathrm{Lmin}-1$ flow rate and $40{ }^{\circ} \mathrm{C}$ column temperature was set. The 3200 QTRAP LC/ MS/MS system (Applied Biosystems, US) was equipped with a Turvo $\mathrm{V}$ electrospray ionization (ESI) interface in positive (DON, T2, AFB1, OTA) and negative (ZON) ion mode was used. Prior to the HPLC-MS/MS measurements, a method was developed and validated. The mycotoxins were separated on a reverse phase $\mathrm{C} 18$ chromatographic column. Two methods were used, the first method included DON, $\mathrm{T} 2$, AFB1 in positive ion mode and ZON in negative ion mode; whist the method included OTA in positive ion mode. The AFB1 and OTA were co-eluting, thus, the researchers chose to measure OTA separately with the same analytical condition as in case of the first method. The chromatograms of the standards are depicted in Fig. S1 (A) and (B). The validation was performed on LB medium. Recoveries for all compounds were between 70 and $114 \%$ with an RSD $<20 \%$. The matrix effect (ion suppression/enhancement) which is the result of the competition between non-volatile matrix components and analyte ions in ESI ion source has also been studied. These effects were between -37 and $+10 \%$, thus, a matrix matched linear calibration curve was used for quantification. LOD values were between 0.2 and $5 \mu \mathrm{g} / \mathrm{kg}$ and LOQ between 1 and $15 \mu \mathrm{g} / \mathrm{kg}$ for all studied mycotoxins. The validation parameters of HPLC-MS/MS method can be observed in Table. S2. The mycotoxin degrading potential of investigated Cupriavidus strains were confirmed by low resolution target HPLC-MS/MS methods. With this instrument, only native mycotoxins with available standards can be qualitatively and quantitatively measured. The metabolomic profile of mycotoxin by-products can be identified with high resolution MS, in further study.

\section{Statistical Analysis}

The statistical analysis was performed with Microsoft Excel 2016 (Microsoft Office, Microsoft Incorporated, US), Past 3 [36] and GraphPad Prism 6.01 (GraphPad Software, San Diego, US). Biological effects were expressed in induction factor (Eq. 1), bioluminescence intensification percent (Eq. 2) and mortality ratio. The residual toxin concentrations determined by HPLCFLD were expressed in $\mathrm{ng} / \mathrm{mL}$. Data were checked for normality with the Shapiro-Wilk normality test and non-compliance with the requirements of parametric methods was established. Significant differences $(P<0.05)$ were verified by one-sample t-tests and Kruskal-Wallis analysis with the Dunn's multiple comparisons test. All values are means of the triplicates. Correlations between biotests and analytical measurements were calculated by Spearman's rank correlation coefficient.

\section{Results}

\section{Biodegradation of AFB1}

Residual AFB1 concentrations were measured by HPLC-MS/MS (Table 2). Four type stains had excellent biodegradation potential. Remarkable (91\%) biodegradation of AFB1 was observed in the case of C. laharis CCUG 53908 ${ }^{\mathrm{T}}$. High AFB1 degradation rates (72-82\%) were demonstrated by $C$. oxalaticus JCM $11285^{\mathrm{T}}$, C. metallidurans CCUG $13724^{\mathrm{T}}$ and $C$. numazuensis DSM $15562^{\mathrm{T}}$ whilst moderate AFB1 reduction (approximately 60\%) was observed in five cases, namely C. taiwanensis CCUG $44338^{\mathrm{T}}$, C. campinensis CCUG $44526^{\mathrm{T}}$, C. pampae CCUG $55948^{\mathrm{T}}$, C. plantarum BCCM/LMG $26296^{\mathrm{T}}$ and C. alkaliphilus BCCM/ LMG $26294^{\mathrm{T}}$. Two strains could detoxify AFB1 for five days according to the SOS-chromotest, C. laharis CCUG $53908^{\mathrm{T}}$ and C. oxalaticus JCM $11285^{\mathrm{T}}(p<0.05)$ (Fig. S3).

In the pellet fraction of $C$. laharis CCUG $53908^{\mathrm{T}} 120 \mathrm{ng} /$ $\mathrm{mL}$ (12\% of the initial toxin concentration) and C. oxalaticus JCM $11285^{\mathrm{T}} 247 \mathrm{ng} / \mathrm{mL}$ ( $24 \%$ of the initial toxin concentration), AFB1 was measured. Adsorption was observed in other cases also and the amount varied between 50 and $254 \mathrm{ng} / \mathrm{mL}$ AFB1 in the pellet as the biodegradation potential was corrected by the residual toxin concentration on the pellet.

\section{Biodegradation and Detoxification of ZON}

According to the analytical results (Table 2), the highest ZON biodegradation rates (82-96\%) were detected in the case of $C$. basilensis RK1 DSM $11853^{\mathrm{T}}, C$. pinatubonensis DSM $19553^{\mathrm{T}}$, C. numazuensis DSM $15562^{\mathrm{T}}$ and C. oxalaticus JCM $11285^{\mathrm{T}}$.

In terms of ZON degradation, the highest toxin concentration on the cell pellet was $155 \mathrm{ng} / \mathrm{mL}$ ( $15 \%$ of the initial toxin concentration), which was observed in the $C$. oxalaticus JCM $11285^{\mathrm{T}}$ strain, which demonstrated a high degradation ability (82\%). In terms of C. basilensis DSM $11853^{\mathrm{T}}$, the pellet ZON concentration was the lowest at $10 \mathrm{ng} / \mathrm{mL}$. The ZON in the pellet varied between 10 and $155 \mathrm{ng} / \mathrm{mL}$ as the biodegradation potential was corrected by the residual toxin concentration on the pellet.

In order to analyse cytotoxicity and the oestrogenic effect of ZON BLYES, tests were performed, respectively. According to the BLYES test (Fig. S4), a considerable 
Table 2 AFB1, ZON, OTA and T-2 biodegradation potential of Cupriavidus type strains after a 5 day-experiment determined by HPLC-MS/MS

\begin{tabular}{|c|c|c|c|c|c|c|}
\hline Species & $\begin{array}{l}\text { AFB1 biodegra- } \\
\text { dation efficiency } \\
(\%)\end{array}$ & $\begin{array}{l}\text { Genotoxic- } \\
\text { ity (IF) } \\
\text { Day } 5\end{array}$ & $\begin{array}{l}\text { ZON biodegrada- } \\
\text { tion efficiency } \\
(\%)\end{array}$ & $\begin{array}{l}\text { Oestrogenic- } \\
\text { ity (Biol. int. } \\
\%)\end{array}$ & $\begin{array}{l}\text { OTA biodegrada- } \\
\text { tion efficiency } \\
(\%)\end{array}$ & $\begin{array}{l}\mathrm{T} 2 \text { biodeg- } \\
\text { radation } \\
\text { efficiency }(\%)\end{array}$ \\
\hline $\begin{array}{l}\text { Cupriavidus alkaliphilus BCCM } \\
26294^{\mathrm{T}}\end{array}$ & 58 & $2.83 \pm 0.14$ & 33 & $1053 \pm 110$ & 95 & 52 \\
\hline Cupriavidus basilensis DSM $11853^{\mathrm{T}}$ & 19 & $2.71 \pm 0.29$ & 96 & $47 \pm 19$ & 94 & 68 \\
\hline $\begin{array}{l}\text { Cupriavidus campinensis CCUG } \\
44526^{\mathrm{T}}\end{array}$ & 61 & $2.60 \pm 0.09$ & 55 & $894 \pm 187$ & 28 & 55 \\
\hline Cupriavidus gilardii JCM $11283^{\mathrm{T}}$ & 32 & $3.45 \pm 0.34$ & 35 & $1140 \pm 9$ & 19 & 95 \\
\hline Cupriavidus laharis CCUG 53908 ${ }^{\mathrm{T}}$ & 91 & $1.31 \pm 0.03$ & 61 & $811 \pm 6$ & 20 & 27 \\
\hline $\begin{array}{l}\text { Cupriavidus metallidurans CCUG } \\
13724^{\mathrm{T}}\end{array}$ & 77 & $2.27 \pm 0.15$ & 51 & $1084 \pm 59$ & 27 & 73 \\
\hline Cupriavidus necator CCUG 52238 & 31 & $3.44 \pm 0.26$ & 47 & $1092 \pm 14$ & 92 & 47 \\
\hline $\begin{array}{l}\text { Cupriavidus numazuensis DSM } \\
15562^{\mathrm{T}}\end{array}$ & 72 & $1.93 \pm 0.11$ & 85 & $530 \pm 16$ & 85 & 70 \\
\hline Cupriavidus oxalaticus JCM $11285^{\mathrm{T}}$ & 82 & $0.97 \pm 0.14$ & 82 & $541 \pm 21$ & 19 & 50 \\
\hline Cupriavidus pampae CCUG $55948^{\mathrm{T}}$ & 60 & $2.82 \pm 0.10$ & 50 & $772 \pm 101$ & 30 & 47 \\
\hline Cupriavidus pauculus JCM $11286^{\mathrm{T}}$ & 41 & $3.04 \pm 0.51$ & 42 & $1118 \pm 90$ & 20 & 42 \\
\hline $\begin{array}{l}\text { Cupriavidus pinatubonensis DSM } \\
19553^{T}\end{array}$ & 17 & $2.90 \pm 0.28$ & 91 & $312 \pm 50$ & 88 & 68 \\
\hline $\begin{array}{l}\text { Cupriavidus plantarum BCCM/LMG } \\
26296^{\mathrm{T}}\end{array}$ & 59 & $2.81 \pm 0.12$ & 67 & $911 \pm 177$ & 14 & 60 \\
\hline $\begin{array}{l}\text { Cupriavidus respiraculi CCUG } \\
46809^{\mathrm{T}}\end{array}$ & 51 & $3.22 \pm 0.12$ & 64 & $310 \pm 34$ & 82 & 47 \\
\hline $\begin{array}{l}\text { Cupriavidus taiwanensis CCUG } \\
44338^{\mathrm{T}}\end{array}$ & 63 & $2.93 \pm 0.20$ & 42 & $636 \pm 215$ & 97 & 56 \\
\hline $\begin{array}{l}\text { Cupriavidus yeoncheonensis JCM } \\
19890^{\mathrm{T}}\end{array}$ & 45 & $3.34 \pm 0.32$ & 41 & $1232 \pm 36$ & 12 & 40 \\
\hline
\end{tabular}

Bold values indicates strains having more than $70 \%$ biodegradation ability

Italic values indicates strains causing biodetoxification

Residual genotoxicity was detected in supernatant by SOS-Chromo test, oestrogenicity was detected by BLYES test

reduction of the oestrogenic effect of $\mathrm{ZON}$ was observed in the strain C. basilensis DSM $11853^{\mathrm{T}}(98 \%)$ compared to the control, which demonstrated a positive correlation with the biodegradation rate in the HPLC analysis. Biodetoxification occurred in the following cases: $C$. respiraculi CCUG $46809^{\mathrm{T}}$ reduced the oestrogenity $(73 \%)$ by the 5 th day, although the degradation was only $64 \%$ as measured by HPLC, which is an extremely effective degradation and detoxification ratio. The C. numazuensis DSM $15562^{\mathrm{T}}$ and C. oxalaticus JCM $11285^{\mathrm{T}}$ could decrease the oestrogenic effect by $50 \%$, with an $85 \%$ biodegradation ratio. C. pinatubonensis DSM $19553^{\mathrm{T}}$ reduced the oestrogenic effect of ZON to approximately $30 \%$ with a $91 \%$ biodegradation rate by day five. Four strains, C. necator CCUG $52238^{\mathrm{T}}$, C. gilardii JCM $11283^{\mathrm{T}}$, C. pauculus $\mathrm{JCM} 11286^{\mathrm{T}}$ and C. yeoncheonensis JCM $19890^{\mathrm{T}}$ had a higher bioluminescence rate (up to $118 \%$ ) compared to the control which leads to the transformation of ZON in additional oestrogenic metabolites.

\section{The Biodegradation of OTA}

Residual OTA concentrations in the supernatant and pellet samples were measured by HPLC-MS/MS. The OTA degradation potential of Cupriavidus type strains differ significantly. Out of the 16 type strains, six strains were the most effective. C. taiwanensis CCUG $44338^{\mathrm{T}}$ demonstrated the highest OTA-reduction rate (97\%), C. alkaliphilus BCCM $26294^{\mathrm{T}}$ showed 95\%, C. basilensis RK1 DSM $11853^{\mathrm{T}}$ showed $94 \%$, C. necator CCUG $52238^{\mathrm{T}}$ showed $92 \%, C$. pinatubonensis DSM $19553^{\mathrm{T}}$ showed $88 \%, C$. numazuensis DSM $15562^{\mathrm{T}}$ showed $85 \%$ and $C$. respiraculi CCUG $46809^{\mathrm{T}}$ showed $82 \%$. Measuring OTA-binding to the cells confirmed that adsorption was negligible. The highest OTA concentration on the cell pellet $(7 \mathrm{ng} / \mathrm{mL}$, $0.7 \%$ of the initial toxin concentration) was observed in case $C$. numazuensis DSM $15562^{\mathrm{T}}$ strain, with a degradation ability of $85 \%$. 


\section{Biodegradation of Trichothecene Mycotoxins}

\section{Biodegradation of T-2}

Out of the 16 type strains, six were able to degrade T-2. The highest biodegradation rate was $95 \%$, which was observed in the case of the $C$. gilardi JCM $11283^{\mathrm{T}}$ strain. Five strains demonstrated a moderate (68-88\%) T-2 biodegradation rate, namely $C$. metallidurans CCUG $13724^{\mathrm{T}}$, C. numazuensis DSM $15562^{\mathrm{T}}$, C. pinatubonensis DSM $1955^{\mathrm{T}}$, C. basilensis DSM $11853^{\mathrm{T}}$ and $C$. plantarum LMG $26296^{\mathrm{T}}$. The T-2 concentration in the pellets was between 22 and $50 \mathrm{ng} / \mathrm{mL}$, this is $2 \%$ and $5 \%$ of the initial toxin concentration, respectively.

\section{Biodegradation of DON}

According to the analytical results, none of the 16 type strains could degrade DON.

\section{Ability to Degrade More than one Mycotoxin}

From the 16 type strains, six were able to degrade $60 \%$ of the two different mycotoxins. The C. respiraculi CCUG $46809^{\mathrm{T}}$ strain could degrade $82 \%$ of OTA and $64 \%$ of ZON. C. laharis CCUG $53908^{\mathrm{T}}$ strain could degrade $91 \%$ of AFB1 and detoxificate the harmful effects of the metabolites as well as degrade $61 \%$ of ZON. The C. metalliduriens CCUG $13724^{\mathrm{T}}$ strains could degrade $77 \%$ of AFB1 and $72 \%$ of T-2. The $C$. plantarum BCCM/LMG $26296^{\mathrm{T}}$ strain could degrade $67 \%$ of ZON and $60 \%$ of T-2. The C. taiwanensis CCUG $44338^{\mathrm{T}}$ strain could degrade $97 \%$ of OTA and $63 \%$ of AFB. The $C$. oxalaticus JCM $11285^{\mathrm{T}}$ strain could degrade $82 \%$ of AFB1 and $82 \%$ of $\mathrm{ZON}$, furthermore, it was able to eliminate the genotoxic effect of AFB1 and its by-products.

The C. pinatubonensis DSM $19553^{\mathrm{T}}$ strain was able to degrade $90 \%$ of ZON, $88 \%$ of OTA and $68 \%$ of T-2. The $C$. basilensis DSM $11853^{\mathrm{T}}$ strain could degrade $96 \%$ of ZON, $94 \%$ of OTA and $68 \%$ of T-2, moreover, in the case of ZON. it could eliminate the oestrogenic effect of the metabolites. The C. numazuensis DSM $15562^{\mathrm{T}}$ strain was the most effective in the degradation of mycotoxins, as it reduced $70 \%$ of T-2, $72 \%$ of AFB $1,85 \%$ of ZON and $85 \%$ of OTA. In order to investigate the detoxification efficiency of three multidegrading strains, the zebrafish embryo microinjection test was conducted to assess the by-products of OTA and T-2.

\section{Zebrafish Embryo Microinjection Test for Evaluating the by-Products of OTA and T-2}

In order to evaluate the biodetoxification in terms of T-2 and OTA, the multi mycotoxin degraders $C$. numazuensis DSM $15562^{\mathrm{T}}$, pinatubonensis DSM $19553^{\mathrm{T}}$ and basilensis DSM $11853^{\mathrm{T}}$ were measured with a newly developed and standardised zebrafish embryo microinjection test method (Csenki et al. 2019). The strains were selected for this method because the C. numazuensis DSM $15562^{\mathrm{T}}$ can degrade four mycotoxins (AFB1, ZON, T-2 and OTA) whilst the $C$. pinatubonensis DSM $19553^{\mathrm{T}}$ and basilensis are able to degrade three mycotoxins (ZON, T-2 and OTA).

According to the microinjection results of the normal metabolites, the strains are toxic for the embryos, with a $60 \%$ mortality ratio indicating a high toxicity level. The source of the strain's toxicity is currently unknown. According to the existing literature, there are no data on the pathogenicity of the Cupriavidus genus amongst fish. The injected supernatants were cell free, without any bacteria, only the centrifuged-filtered inocula containing the by-products and metabolites of the strains. The pellets of the inocula were also investigated by the HPLC, where the residual T- 2 concentration was only $2-5 \%$ of the initial toxin concentration.

With regards to the T-2 microinjection test, $C$. pinatubonensis DSM $19553^{\mathrm{T}}$ demonstrated a significant reduction at $4.17 \mathrm{~nL}$ injected volume $(p<0.01)$ in the mortality compared to the $7 \mathrm{mg} / \mathrm{L} \mathrm{T}-2$ control. Although the bacteria strain reduced the lethality rate, the degraded metabolites were toxic to zebrafish (mortality rate: $40 \%$ ) (Fig. 2). The effect of the T-2 metabolites ratio was less than the metabolites effect revealed in Fig. 3.

In terms of the OTA microinjection test, $C$. numazuensis DSM $15562^{\mathrm{T}}$ demonstrated a significant decrease at $4.17 \mathrm{~nL}$ injected volume $(p<0.01)$ in the mortality rate compared to the $7 \mathrm{mg} / \mathrm{L}$ OTA control. Although the bacteria strain reduced the lethality rate, the degraded metabolites were toxic to zebrafish (mortality rate: $45 \%$ ) (Fig. 4). The effect

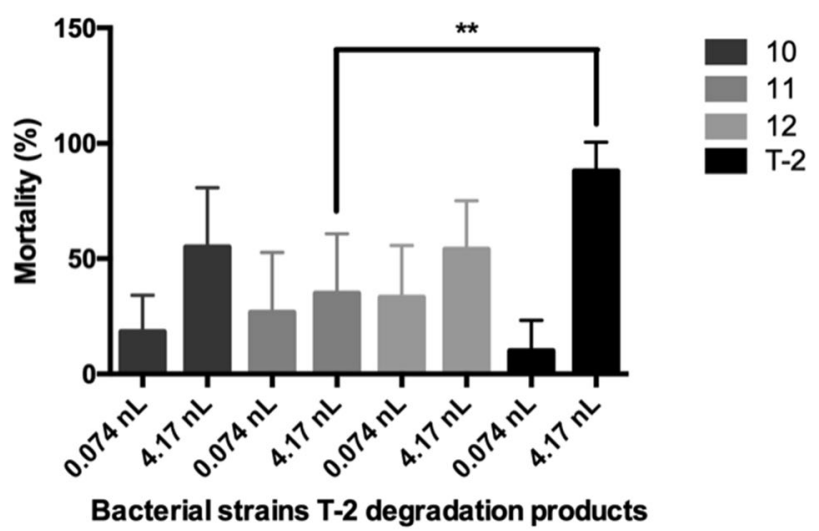

Fig. 2 Bacterial strains T-2 degradation products were injected with $0.074 \mathrm{~nL}$ and $4.17 \mathrm{~nL}$ volumes. All strains degradation products were toxic on zebrafish embryos. Statistically significant differences were detected between 11 strain and T-2 $(p<0.01)$ at $4.17 \mathrm{~nL}$ injected volume. Number 10 was $C$. numazuenzis DSM $15562^{\mathrm{T}}, 11$ was $C$. pinatubonensis DSM $19553^{\mathrm{T}}$, 12 was $C$. basilensis DSM $11853^{\mathrm{T}}$ type strain 


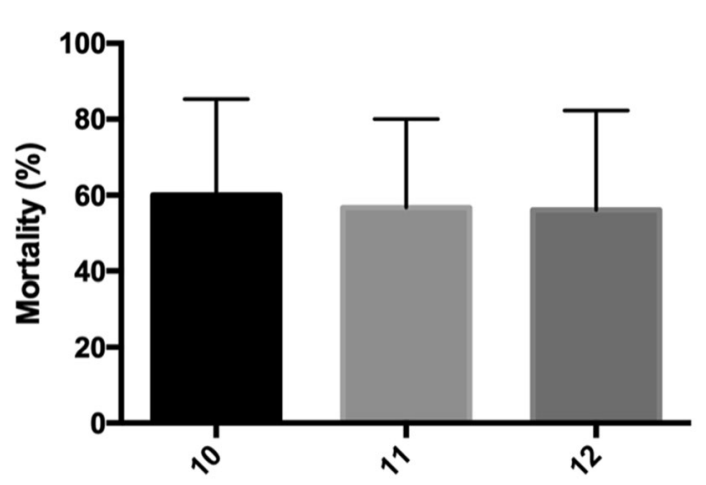

Bacterial strains metabolites

Fig. 3 Bacterial strains metabolites were injected with $4.17 \mathrm{~nL}$ volume. All strains were toxic on zebrafish embryos. Statistically significant differences were not detected between strains. Number 10 was $C$. numazuenzis DSM $15562^{\mathrm{T}}$, 11 was $C$. pinatubonensis DSM $19553^{\mathrm{T}}$, 12 was $C$. basilensis DSM $11853^{\mathrm{T}}$ type strain

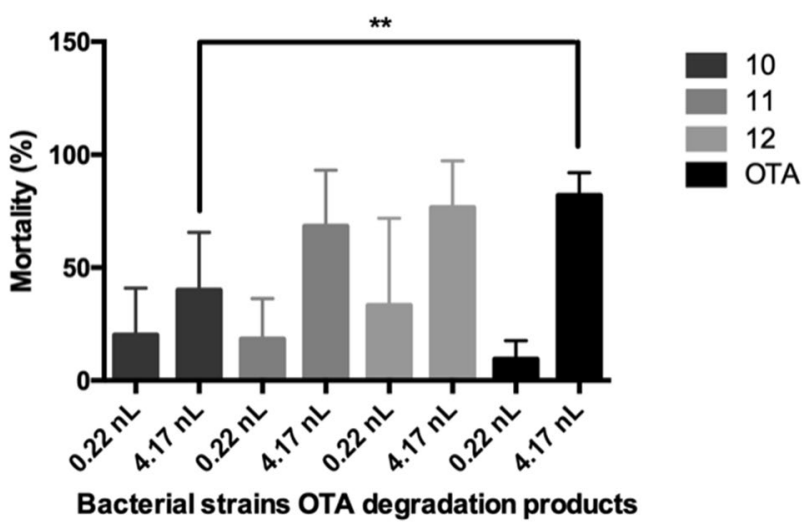

Fig. 4 Bacterial strains OTA degradation products were injected with $0.22 \mathrm{~nL}$ and $4.17 \mathrm{~nL}$ volumes. All strains degradation products were toxic on zebra fish embryos. Statistically significant differences were detected between 10 strain and OTA $(p<0.01)$ at $4.17 \mathrm{~nL}$ injected volume. Number 10 was $C$. numazuenzis DSM $15562^{\mathrm{T}}, 11$ was $C$. pinatubonensis DSM $19553^{\mathrm{T}}$, 12 was $C$. basilensis DSM $11853^{\mathrm{T}}$ type strain

of OTA metabolites ratio was less than the metabolites effect depicted in Fig. 3.

\section{Discussion}

In the present study, the aim was to measure the mycotoxin biodegradation potential of 16 type strains of Cupriavidus genus and evaluate the potential harmful effects of the metabolic intermediates. The research also aimed to select the best degraders amongst these strains.

The mycotoxin degradation ability of different bacteria (Rhodococcus sp, Streptomyces sp) was previously investigated by this department [30, 37, 38]. Members of the Cupriavidus genus have profound abilities in terms of the biodegradation of different chemicals and xenobiotics, particularly one mycotoxin OTA [7]. The biodegradation experiments were performed within five days because of the comparison of the aforementioned existing studies. Although the biodegradation result was confirmed after two or three days and the researchers also realised the 95\% AFB1 biodegradation rate for $24 \mathrm{~h}$, the present study is the first evaluation of the Cupriavidus genus biodegradation ability in terms of mycotoxins.

The comparison of the biodegradation potential of different bacteria is not the most appropriate foundation because biodegradation does not necessary signify biodetoxification, which refers to the elimination of the harmful effects of the biodegraded chemical. The comparison of the biodetoxification ability is an appropriate method. However, evaluation of the biodetoxification is challenging because an appropriate biotest or organism is required. Mycotoxins have different negative effects, which are not easy to measure or estimate realistically due to cost effectiveness, time and resources. Unfortunately, only limited publications have investigated biodetoxification in terms of biodegradation.

In terms of AFB1, Rhodococcus sp are highly effective biodetoxifiers from 42 type strains of which 15 terminated the genotoxicity in $72 \mathrm{~h}$. With regards to $\mathrm{ZON}$, only one Rhodococcus type strain could terminate the eostrogenic effect [30]. 124 Streptomyces strains were tested for AFB1 and ZON biodegradation, and only one strain was able to biodetoxify AFB1 and only two strains could terminate the eostrogenic effect of ZON [38].

From the genus Cupriavidus, almost all the type strains are able to biodegrade AFB1 in five days and a high biodegradation ratio (over $70 \%$ ) was achieved by only four strains, namely $C$. laharis CCUG $53908^{\mathrm{T}}(91 \%)$, C. oxalaticus JCM $11285^{\mathrm{T}}(82 \%)$, C. metallidurans CCUH $13724^{T}(77 \%)$ and $C$. numazuensis DSM $15562^{\mathrm{T}}(72 \%)$. According to the SOS-chromotest results, two strains were able to terminate the genotoxicity. These were C. laharis CCUG $53908^{\mathrm{T}}$ $(\mathrm{IF}=1.31)$ and $C$. oxalaticus $\mathrm{JCM} 11285^{\mathrm{T}}(\mathrm{IF}=0.97)$. The biodegradation and biodetoxification was observed, and absorption on the pellet was not assuming an integral role as in the case of the elimination of AFB1. In Fig. S3, high degradation ratios can be observed. In the absence of the eliminations of the genotoxic effect in the case of 14 strains, all degradation results were corrected with the residual AFB1 concentration measured on the pellets. Only the aforementioned C. laharis CCUG $53908^{\mathrm{T}}$ and C. oxalatixus JCM $11285^{\mathrm{T}}$ were able to terminate the genotoxicity.

In the case of ZON, all Cupriavidus strains had biodegradation ability, but only four attained a $70 \%$ rate, namely C. basilensis DSM $11853^{\mathrm{T}}(95 \%)$, C. pinatubonensis DSM $19553^{\mathrm{T}}(91 \%)$, C. numazuensis DSM $15562^{\mathrm{T}}(85 \%)$ and $C$. 
oxalaticus JCM $11285^{\mathrm{T}}$ (82\%). According to the BLYES results, one strain was able to reduce the endocrine disrupting effect of the metabolites of ZON, namely the C. basilensis RK1 DSM $11853^{\mathrm{T}}$ strain (Fig. S4).

Comparing the results of the present study with the Rhodococcus genus ability, the genus Cupriavidus has less appropriate members for detoxifying the mycotoxins, but still a valuable resource for further research and for future application against mycotoxins.

From the 16 type strains, in the case of OTA, there were two groups, namely strains with a weak biodegradation ability $(30 \%)$ and strains with a remarkable biodegradation potential (over $80 \%$ ). The most effective strains were $C$. taiwanensis CCUG $44338^{T}$ (97\%), C. alkaliphilus BCCM $26294^{T}$ (95\%), C. basilensis (94\%), C. necator (92\%), C. pinatubonensis (88\%), C. numazuensis (85\%) and C. respiculi (82\%). The evaluation of the biodetoxification ability of theses strains are limited, because there are only difficult and time-consuming biotests or methods for testing the negative effects of the OTA by-products. In the case of the Cupriavidus basilensis ÖR16 wild strain, which has a remarkable 98\% OTA biodegradation and biodetoxification ability, the first biotest was a mice feeding experiment performed by Ferenczi et al. in 2014. This method took approximately two months with a 21-day long feeding experiment, and one month for evaluating the results on the level of gene expression, weight and biopsy. ÖR16 strain was biodetoxifing the OTA effectively in five days. No harmful effects were observed. The ÖR16 strain was also tested by a novel Danio rerio embryo microinjection method developed by Csenki et al. [35], the test required approximately seven days to obtain the results. In this test, the strain by-products had the same effect as the results of this research and it caused 50\% mortality amongst the embryos. However, the OTA biodegraded supernatant was less harmful than the OTA control and the normal by-product control.

The strain C. basilensis DSM $11853^{\mathrm{T}}$ was tested for biodetoxification of OTA using a Danio rerio microinjection test. According to the results, it is not able to decrease the harmful effect of the OTA by-products, although it demonstrated a $94 \%$ toxin degradation. C. numazuensis DSM $15562^{\mathrm{T}}$ was also evaluated by the microinjection test, where the strain OTA by-product had a significantly reduced harmful effect in comparison to the OTA containing control.

In terms of the T-2 toxin, only six strains could biodegrade T-2 with a ratio exceeding $60 \%$, namely $C$. gilardii JCM $11283^{\mathrm{T}}(95 \%)$, C. metallidurans CCUG $13724^{\mathrm{T}}(73 \%)$, C. numazuensis DSM $15562^{\mathrm{T}}(70 \%)$, C. pinatubonensis DSM $19553^{\mathrm{T}}(68 \%)$, C. basilensis RK1 DSM $11853^{\mathrm{T}}(68 \%)$ and $C$. plantarum BCM/LMG $26296^{\mathrm{T}}(60 \%)$. The evaluation of the T-2 detoxification has an identical problem with the OTA. In the case of the three strains, the researchers used the microinjection test for evaluation of the detoxification.
In terms of the $C$. pinatubonensis DSM $19553^{\mathrm{T}}$, the T-2 byproducts were significantly less harmful than the T-2 control, according to the results. Biodegradation of DON was also investigated but none of the 16 type strains were able to degrade it.

From the 16 type strains, five strains were able to degrade two or more mycotoxins effectively (over $60 \%$ ). The $C$. metallidurans CCUG $13724^{\mathrm{T}}$ could biodegrade AFB1 and T-2. The C. oxalaticus JCM $11285^{\mathrm{T}}$ could degrade AFB1 and ZON. The C. pinatubonensis DSM $19553^{\mathrm{T}}$ and $C$. basilensis RK1 DSM $11853^{\mathrm{T}}$ could degrade ZON, OTA and T-2. The C. numazuensis DSM $15562^{\mathrm{T}}$ was able to biodegrade four mycotoxins, namely AFB1, ZON, OTA and T-2. This phenomenon is unique according to the existing literature. To date, Rhodococcus strains are known to degrade and detoxify more than two mycotoxins, for example, $R$. erythropolis $\mathrm{NI} 1$ strain can biodegrade AFB1, ZON and T-2 and detoxify the harmful effects of AFB1 and ZON [30]. A microbe consortia TMDC was investigated recently, which was able to simultaneously degrade AFB 1 and ZEA in excess of $90 \%$ after $72 \mathrm{~h}$ but the detoxification was not evaluated. The consortia was comprised of the following generea Geobacillus, Tepidimicrobium, Clostridium, Aeribacillus, Cellulosibacter, Desulfotomaculum and Tepidanaerobacter [39].

The C. pinatubonensis DSM $19553^{\mathrm{T}}$, C. numazuensis DSM $15562^{\mathrm{T}}$ and C. basilensis RKI DSM $11853^{\mathrm{T}}$ species were selected for a teratogenicity test using a Danio rerio embryo microinjection. According to the results, metabolites of these three strains were also toxic to the embryos and the mortality was $60 \%$ in all cases. This result resembles that of the $C$. basilensis ÔR16 wild strain [7] because the mortality was $50 \%$ in that case also. It appears that the members of the Cupriavidus genus have some toxic-by-product for fish embryos because the injected inocula was cell free. There is no information stating that Cupriavidus strains are pathogenic for fish.

In terms of the $C$. numazuensis DSM $15562^{\mathrm{T}}$ strain, the harmful effect of the toxin by-products was significantly less than the OTA control. A similar result was observed with $\mathrm{T}-2$ detoxification by the $C$. pinatubonensis DSM $19553^{\mathrm{T}}$ strain. In both cases, the mortality ratio induced by the toxin breakdown products was less than with the bacterial metabolites.

Ultimately, according to the results, the Cupriavidus genus mycotoxin biodegradation ability could be a promising advantage in the future. At present, 11 type strains have genome project data. If all the members of the genus had full genome project data, it could be combined with the results of the present study and the responsible genes for mycotoxins biodegradation can be identified. This will help develop a cell free enzyme-based additive for treating the contaminated feed or crop. 
The validation of the detoxification in the case of T-2 and OTA degrading members, and the investigation of the simultaneous mycotoxin degradation and detoxification should be implemented.

Acknowledgements Open access funding provided by Szent István University (SZIE). This work was supported by the Development and Innovation Fund (NKFIA); Grant Agreement: NVKP_16-1-20160009 and the Higher Education Institutional Excellence Program (17833/2018/FEKUTSTRAT) by the Ministry of Human Capacities projects. Mátyás Cserháti was also supported by the Bolyai János Postdoctoral Fellowship provided by the Hungarian Academy of Science. We are thankful to BSc student, Ákos Suhajda for helping during the experiments in the laboratory.

Author contributions $\mathrm{MN}$ contributed to the biodegradation experiment and the writing of this paper, with MC who conceived and designed the present study. AR was responsible for the SOS-chromo and BLYES tests. EG and ZCB contributed to the microinjection test. Emese Varga accomplished the analytical measurements. BK and IS contributed to the analysis and interpretation of the results. All the researchers have approved the final version for submission.

\section{Compliance with Ethical Standards}

Conflict of interest The researchers have declared that there is no potential conflict of interest.

Open Access This article is licensed under a Creative Commons Attribution 4.0 International License, which permits use, sharing, adaptation, distribution and reproduction in any medium or format, as long as you give appropriate credit to the original author(s) and the source, provide a link to the Creative Commons licence, and indicate if changes were made. The images or other third party material in this article are included in the article's Creative Commons licence, unless indicated otherwise in a credit line to the material. If material is not included in the article's Creative Commons licence and your intended use is not permitted by statutory regulation or exceeds the permitted use, you will need to obtain permission directly from the copyright holder. To view a copy of this licence, visit http://creativecommons.org/licenses/by/4.0/.

\section{References}

1. Coenye T, Vandamme P, Lipuma JJ (2003) Ralstonia respiraculi sp. nov., isolated from the respiratory tract of cystic fibrosis patients. Int J Syst Evol Microbiol 53:1339-1342

2. Goris J, De Vos P, Coenye T, Hoste B, Janssens D, Brim H, Diels L, Mergeay M, Kersters K, Vandamme P (2001) Classification of metal-resistant bacteria from industrial biotopes as Ralstonia campinensis sp. nov., Ralstonia metallidurans sp. nov. and Ralstonia basilensis Steinle et al. 1998 emend. Int J Syst Evol Microbiol 51:1773-1782. https://doi.org/10.1099/00207713-51-5-1773

3. Janssen PJ, Van Houdt R, Moors H, Monsieurs P, Morin N, Michaux A, Benotmane MA, Leys N, Vallaeys T, Lapidus A, Monchy S, Medigue C, Taghavi S, McCorkle S, Dunn J, van der Lelie D, Mergeay M (2010) The complete genome sequence of Cupriavidus metallidurans strain $\mathrm{CH} 34$, a master survivalist in harsh and anthropogenic environments. PLoS ONE 5:e10433. https://doi.org/10.1371/journal.pone.0010433

4. Perez-Pantoja D, De la Iglesia R, Pieper DH, Gonzalez B (2008) Metabolic reconstruction of aromatic compounds degradation from the genome of the amazing pollutant-degrading bacterium Cupriavidus necator JMP134. FEMS Microbiol Rev 32:736-794. https://doi.org/10.1111/j.1574-6976.2008.00122.x

5. Cuadrado V, Gomila M, Merini L, Giulietti AM, Moore ERB (2010) Cupriavidus pampae sp. nov., a novel herbicide-degrading bacterium isolated from agricultural soil. Int J Syst Evol Microbiol 60:2606-2612. https://doi.org/10.1099/ijs.0.018341-0

6. Lykidis A, Pérez-Pantoja D, Ledger T, Mavromatis K, Anderson IJ, Ivanova NN, Hooper SD, Lapidus A, Lucas S, González B, Kyrpides NC (2010) The complete multipartite genome sequence of Cupriavidus necator JMP134, a versatile pollutant degrader. PLoS ONE 5:e9729. https://doi.org/10.1371/journal.pone.00097 29

7. Ferenczi S, Cserháti M, Krifaton C, Szoboszlay S, Kukolya J, Szoke Z, Koszegi B, Albert M, Barna T, Mézes M, Kovács KJ, Kriszt B (2014) A new ochratoxin a biodegradation strategy using Cupriavidus basilensis Or16 strain. PLoS ONE. https:// doi.org/10.1371/journal.pone.0109817

8. Chen W-M, Laevens S, Lee T-M, Coenye T, De Vos P, Mergeay M, Vandamme P (2001) Ralstonia taiwanensis sp. nov., isolated from root nodules of lemphMimosa species and sputum of a cystic fibrosis patient. Int J Syst Evol Microbiol 51:1729-1735. https://doi.org/10.1099/00207713-51-5-1729

9. Ogawa N, Miyashita K (1999) The chlorocatechol-catabolic transposon Tn 5707 of Alcaligenes eutrophus NH9, carrying a gene cluster highly homologous to that in the 1,2, 4-Trichlorobenzene-degrading bacterium Pseudomonas sp. strain P51, confers the ability to grow on 3-chloroben. Appl Environ Microbiol 65:724-731

10. Morimoto S, Togami K, Ogawa N, Hasebe A, Fujii T (2005) Analysis of a bacterial community in 3-chlorobenzoate-contaminated soil by PCR-DGGE targeting the 16S rRNA gene and benzoate 1,2-dioxygenase gene (benA). Microbe Environ 20(3):151-159. https://doi.org/10.1264/jsme2.20.151

11. Kageyama C, Ohta T, Hiraoka K, Suzuki M, Okamoto T, Ohishi K (2005) Chlorinated aliphatic hydrocarbon-induced degradation of trichloroethylene in Wautersia numadzuensis sp. nov. Arch Microbiol 183(1):56-65. https://doi.org/10.1007/s0020 3-004-07465

12. Koopman F, Wierckx N, Winde JHD, Ruijssenaars HJ (2010) Identification and characterization of the furfural and 5- ( hydroxymethyl ) furfural degradation pathways of Cupriavidus basilensis HMF14 107. Proc Natl Acad Sci USA. https://doi.org/10.1073/ pnas.0913039107

13. Fischer J, Kappelmeyer U, Kastner M, Schauer F, Heipieper HJ (2010) The degradation of bisphenol A by the newly isolated bacterium Cupriavidus basilensis JF1 can be enhanced by biostimulation with phenol. Int Biodet Biodegrad 64:324-330. https://doi. org/10.1016/j.ibiod.2010.03.007

14. Stamper DM, Radosevich M, Hallberg KB, Traina SJ, Tuovinen OH (2003) Ralstonia basilensis M91-3, a denitrifying soil bacterium capable of using $\mathrm{s}$-triazines as nitrogen sources. Can J Microbiol 1098:1089-1098. https://doi.org/10.1139/W02-113

15. Zilouei H, Soares A, Murto M, Guieysse B, Mattiasson B (2006) Influence of temperature on process efficiency and microbial community response during the biological removal of chlorophenols in a packed-bed bioreactor. Appl Microbiol Biotechnol 72:591-599. https://doi.org/10.1007/s00253-005-0296-Z

16. Shi Y, Chai L, Tang C, Yang Z, Zhang H, Chen R, Chen Y, Zheng $\mathrm{Y}$ (2013) Characterization and genomic analysis of kraft lignin biodegradation by the beta-proteobacterium Cupriavidus basilensis B-8. Biotechnol Biofuels 6:1

17. Steinle P, Stucki G, Stettler R, Hanselmann KW (1998) Aerobic mineralization of 2, 6-dichlorophenol by Ralstonia sp. strain RK1. Appl Environ Microbiol 64:2566-2571 
18. Wang X, Chen M, Xiao J, Hao L, Crowley DE, Zhang Z, Yu J, Huang N, Huo M, Wu J (2015) Genome sequence analysis of the naphthenic acid degrading and metal resistant bacterium Cupriavidus gilardii CR3. PLoS ONE 10(8):e0132881. https://doi. org/10.1371/journal.pone.0132881

19. Takahito W, Atsushi Y, Akira H, Hidehiko F, Hikaru S, Jun H, Taiki F, Masatoshi G, Nobutada K, Kensuke F (2015) Draft genome sequence of Cupriavidus pauculus strain KF709, a biphenyl-utilizing bacterium isolated from biphenyl-contaminated soil. ASM Mycrobiol. https://doi.org/10.1128/genomeA.00222-15

20. Sun LN, Wang DS, Yang ED, Fang LC, Chen YF, Tang XY, Hua RM (2006) Cupriavidus nantongensis sp. nov., a novel chlorpyrifos-degrading bacterium isolated from sludge. Int J Syst Evol Microbiol 66:2335

21. Pohlmann A, Fricke WF, Reinecke F et al (2006) Genome sequence of the bioplastic-producing "Knallgas" bacterium Ralstonia eutropha H16. Nat Biotechnol 24:1257-1262. https://doi. org/10.1038/nbt1244

22. Trefault N, De la Iglesia R, Molina AM et al (2004) Genetic organization of the catabolic plasmid pJP4 from Ralstonia eutropha JMP134 (pJP4) reveals mechanisms of adaptation to chloroaromatic pollutants and evolution of specialized chloroaromatic degradation pathways. Environ Microbiol 6:655-668. https ://doi.org/10.1111/j.1462-2920.2004.00596.x

23. Bhat R, Rai RV, Karim AA (2010) Mycotoxins in food and feed: present status and future concerns. Compr Rev Food Sci Food Saf 9:57-81. https://doi.org/10.1111/j.1541-4337.2009.00094.x

24. Marroquín-Cardona AG, Johnson NM, Phillips TD, Hayes AW (2014) Mycotoxins in a changing global environment-a review. Food Chem Toxicol 69:220-230. https://doi.org/10.1016/j. fct.2014.04.025

25. McKenzie KS, Sarr AB, Mayura K, Bailey RH, Miller DR, Rogers TD, Norred WP, Voss KA, Plattner RD, Kubena LF, Phillips TD (1997) Oxidative degradation and detoxification of mycotoxins using a novel source of ozone. Food Chem Toxicol 35(8):807-820

26. Grenier, B., Loureiro-Bracarense, A.-P., Leslie, J.F., Oswald, I.P., 2014. Physical and chemical methods for mycotoxin decontamination in maize, In: Mycotoxin reduction in grain chains. Wiley, Hoboken, pp. 116-129

27. Schatzmayr G, Rodrigues I, Krska R, Ottner F, Fruhauf S, Bermudez AJ, Rottinghaus GE, Vekiru E, Ledoux DR (2015) In vitro binding assessment and in vivo efficacy of several adsorbents against aflatoxin B 1. World Mycotoxin J 8:477-488. https://doi. org/10.3920/wmj2014.1800

28. Boudra H, Morgavi D, Burel C, Pussemier L, Prigent P, Debongnie P, Fremy J, Dragacci S, Perez A, Boudergue C, Oswald I, Massimi C, Avantaggiato G, Favrot M (2017) Review of mycotoxin, detoxifying agents used as feed additives: mode of action, efficacy and feed/food safety. EFSA Support Publ. https://doi.org/10.2903/ sp.efsa.2009.en-22
29. Quillardet P, Huisman O, D’Ari R, Hofnung M (1982) SOS chromotest, a direct assay of induction of an SOS function in Escherichia coli $\mathrm{K}-12$ to measure genotoxicity. Proc Natl Acad Sci USA 79:5971-5975. https://doi.org/10.1073/pnas.79.19.5971

30. Risa A, Krifaton C, Kukolya J, Kriszt B, Cserháti M, Táncsics A (2018) Aflatoxin B1 and zearalenone-detoxifying profile of rhodococcus type strains. Curr Microbiol 75:907-917. https://doi. org/10.1007/s00284-018-1465-5

31. Legault R, Blaise C (1994) Comparative assessment of the SOS chromotest kit and the mutatox test with the Salmonella plate incorporation (Ames Test ) and fluctuation tests for screening genotoxic agents. Environ Toxicol Water Qual 9:45-57

32. Sanseverino J, Gupta RK, Layton AC, Patterson SS, Ripp SA, Saidak L, Simpson ML, Schultz TW, Sayler GS (2008) Use of Saccharomyces cerevisiae BLYES expressing bacterial bioluminescence for rapid, sensitive detection of estrogenic compounds. Appl Environ Microbiol 71:4455-4460. https://doi.org/10.1128/ AEM.71.8.4455

33. Quillardet P, Hofnung M (1985) The SOS chromotest, a colorimetric bacterial assay for genotoxins: procedures. Mutat Res 147:65-78. https://doi.org/10.1016/0165-1161(85)90020

34. Krifaton C, Kriszt B, Szoboszlay S, Cserhati M, Szucs A, Kukolya J (2011) Mutation research/genetic toxicology and environmental mutagenesis analysis of aflatoxin-B1-degrading microbes by use of a combined toxicity-profiling method. Mutat Res 726:1-7. https ://doi.org/10.1016/j.mrgentox.2011.07.011

35. Csenki Z, Garai E, Risa A, Cserháti M, Bakos K, Márton D, Bokor Z, Kriszt B, Urbányi B (2019) Biological evaluation of microbial toxin degradation by microinjected zebrafish (Danio rerio) embryos. Chemosphere 227:151-161. https://doi.org/10.1016/j. chemosphere.2019.04.014

36. Hammer O, Harper DAT, Ryan PD (2001) PAST: paleontological statistics software package for education and data analysis. Palaeontol Electron 4:9

37. Cserháti M, Kriszt B, Krifaton C et al (2013) Mycotoxin-degradation profile of Rhodococcus strains. Int J Food Microbiol 166:176-185. https://doi.org/10.1016/j.ijfoodmicro.2013.06.002

38. Harkai P, Szabó I, Cserháti M et al (2016) Biodegradation of aflatoxin-B1 and zearalenone by Streptomyces sp. collection. Int Biodet Biodegrad 108:48-56. https://doi.org/10.1016/j.ibiod .2015.12.007

39. Wang Y, Zhao C, Zhang D, Zhao M, Zheng D, Peng M, Cheng W, Guo P, Cui Z (2018) Simultaneous degradation of aflatoxin B1 and zearalenone by a microbial consortium, Toxicon, 146, 69-76, ISSN 0041-0101, https://doi.org/10.1016/j.toxicon.2018.04.007

Publisher's Note Springer Nature remains neutral with regard to jurisdictional claims in published maps and institutional affiliations. 